\title{
Generic Phosphatase Activity Detection using Zinc Mediated Aggregation Modulation of Polypeptide-Modified Gold Nanoparticles
}

Robert Selegård, Karin Enander and Daniel Aili

\author{
Linköping University Post Print
}

Tweet

N.B.: When citing this work, cite the original article.

Original Publication:

Robert Selegård, Karin Enander and Daniel Aili, Generic Phosphatase Activity Detection using Zinc Mediated Aggregation Modulation of Polypeptide-Modified Gold Nanoparticles, 2014, Nanoscale, (6), 23, 14204-14212.

http://dx.doi.org/10.1039/c4nr02791d

Copyright: Royal Society of Chemistry http://www.rsc.org/

Postprint available at: Linköping University Electronic Press

http://urn.kb.se/resolve?urn=urn:nbn:se:liu:diva-106718 


\section{ARTICLE}

Cite this: DOI: $10.1039 / \times 0 x x 00000 x$

Received 00th January 2012 Accepted 00th January 2012

DOI: 10.1039/x0xx00000x

www.rsc.org/

\section{Generic Phosphatase Activity Detection using Zinc Mediated Aggregation Modulation of Polypeptide- Modified Gold Nanoparticles}

\author{
Robert Selegård, Karin Enander, Daniel Aili*
}

A challenge in the design of plasmonic nanoparticle-based colorimetric assays is that the change in colloidal stability, which generates the colorimetric response, is often directly linked to the biomolecular recognition event. New assay strategies are hence required for every type of substrate and enzyme of interest. Here, a generic strategy for monitoring of phosphatase activity is presented where substrate recognition is completely decoupled from the nanoparticle stability modulation mechanism, which enables detection of a wide range of enzymes using different natural substrates with a single simple detection scheme. Phosphatase activity generates inorganic phosphate that forms an insoluble complex with $\mathrm{Zn}^{2+}$. In a sample containing a preset concentration of $\mathrm{Zn}^{2+}$, phosphatase activity will markedly reduce the concentration of dissolved $\mathrm{Zn}^{2+}$ from the original value, which in turn affects the aggregation of gold nanoparticles functionalized with a designed $\mathrm{Zn}^{2+}$ responsive polypeptide. The change in nanoparticle stability thus provides a rapid and sensitive readout of the phosphatase activity. The assay is not limited to a particular enzyme or enzyme substrate, which is demonstrated using three completely different phosphatases and five different substrates, and thus constitutes a highly interesting system for drug screening and diagnostics.

\section{Introduction}

The high-energy phosphate ester bonds in nucleoside $5^{\prime}$ triphosphates (NTPs) are the primary energy carriers in cells and are consumed and produced in a countless number of metabolic reactions as the need for energy fluctuates. NTPs are not only ubiquitous energy donors but are also involved in numerous other critically important processes. Adenosine 5'triphosphate (ATP) is a neurotransmitter and an essential component in the purinergic signaling system which regulates cellular functions through autocrine and paracrine activation of nucleotide receptors, ${ }^{1,2}$ while guanosine $5^{\prime}$-triphosphate (GTP) is involved in G-protein mediated cellular signaling, ${ }^{3}$ protein synthesis, ${ }^{4}$ and vesicular transport. ${ }^{5}$ The phosphate ester bond is also present in pyrophosphate $\left(\mathrm{PP}_{\mathrm{i}}\right)$, which in higher organisms is generated by metabolic degradation of NTPs, and plays a critical role in regulating extracellular matrix calcification. In certain lower organisms it can act as an ATP substitute under anaerobic conditions. ${ }^{6}$ Both intra and extracellular levels of these phosphate ester-containing compounds (from now on denoted $\mathrm{PP}_{\mathrm{x}}$ ) are regulated and hydrolyzed by a large number of phosphatases, releasing inorganic phosphates $\left(\mathrm{P}_{\mathrm{i}}\right)$ as byproducts. The human genome is also encoding for hundreds of different protein phosphatases that hydrolyze phosphoric monoester modifications of proteins and that act in concert with kinases to regulate a plethora of critically important cellular processes such as metabolic activity, ${ }^{7}$ cell motility, ${ }^{8}$ cell survival and cell death. ${ }^{9}$ Assays that can monitor phosphatase activity can thus be used to characterize a vast number of fundamentally important enzymatic reactions and potential drug targets and are regularly used for diagnosis of a range of diseases, and are consequently of immense importance for biomedical research, drug development, and diagnostics.

Conventional methods for monitoring phosphatase mediated hydrolysis of NTP and $\mathrm{PP}_{\mathrm{i}}$ exploit synthetic substrate analogues that produce a change in color, ${ }^{10}$ luminesce ${ }^{11}$ or fluorescence ${ }^{12}$ when hydrolyzed. Although sensitive, these types of assay are subjected to interference from compounds in the sample with similar optical properties. Moreover, they rely on the use of non-natural substrates that can give an erroneous interpretation of enzymatic activity.

The use of gold nanoparticles (AuNPs) as transducers in colorimetric assays has received considerable attention due to their unique optical properties, tunable surface chemistry and potentially very high sensitivity. ${ }^{13-15}$ In particular the colorimetric response generated as a consequence of aggregation or redispersion of AuNPs has been utilized in a wide range of applications, including detection of enzymes, ${ }^{16-18}$ nucleotides, ${ }^{19}$ and metal cations. ${ }^{20,21}$ Assays for the detection of phosphatase activity have also been reported but either use nonfunctionalized AuNPs that are prone to unspecific aggregation 
or are restricted to the use of a specific substrate. ${ }^{22-24}$ The latter reflects a general problem in design of AuNP-based assays; that the change in colloidal stability is directly linked to the biomolecular recognition event. New assay strategies are thus required for every type of substrate and enzyme of interest, which is both time-consuming and expensive. Here, we present a generic AuNP-based strategy for monitoring of enzymatic $\mathrm{PP}_{\mathrm{x}}$ hydrolysis where substrate recognition is completely decoupled from the nanoparticle stability modulation mechanism, which enables detection of a wide range of enzymes using different natural substrates and a single detection scheme.

$\mathrm{PP}_{\mathrm{x}}$ and other phosphate containing species have in common that they readily coordinate metal cations such as $\mathrm{Mg}^{2+}, \mathrm{Mn}^{2+}$ and $\mathrm{Zn}^{2+} .{ }^{25}, 26$ In fact, virtually all reactions involving NTPs also involve metal cations directly coordinated to the nucleotides or as integrated cofactors in the hydrolytic enzymes. ${ }^{27}$ Even though the coordination capacity varies between different $\mathrm{PP}_{\mathrm{x}}$ species, they have in common that $\mathrm{P}_{\mathrm{i}}$ is generated when they are hydrolyzed. The coordination capacity of $\mathrm{P}_{\mathrm{i}}$ for $\mathrm{Zn}^{2+}$ is higher compared to the starting materials, and the resulting complex, $\left[\mathrm{Zn}_{3}\left(\mathrm{PO}_{4}\right)_{2}\right]$, is virtually insoluble. Enzymatic hydrolysis of $\mathrm{PP}_{\mathrm{x}}$ to $\mathrm{P}_{\mathrm{i}}$ hence provides a mechanism to regulate the concentration of dissolved $\mathrm{Zn}^{2+}$ in a sample. In our approach to monitoring enzymatic $\mathrm{PP}_{\mathrm{x}}$ hydrolysis, we exploit this mechanism to tune the colloidal stability of AuNPs functionalized with a $\mathrm{Zn}^{2+}$ responsive de novo designed polypeptide. The enzymatic generation of $P_{i}$ and the subsequent formation of insoluble $\mathrm{Zn}^{2+}$ complexes reduces the concentration of $\mathrm{Zn}^{2+}$ available to the polypeptide, which has a dramatic effect on the stability of the AuNPs. Aggregation of the polypeptide-functionalized AuNPs is triggered in a rather narrow $\mathrm{Zn}^{2+}$ concentration interval as a consequence of a $\mathrm{Zn}^{2+}$ induced folding of the immobilized polypeptides. ${ }^{21}$ Even very subtle changes in the concentration of $\mathrm{Zn}^{2+}$ can result in drastic changes in the AuNP aggregation, which affects the localized surface plasmon resonance (LSPR) band, producing a colorimetric response. By maintaining a constant concentration of both $\mathrm{Zn}^{2+}$ and $\mathrm{PP}_{\mathrm{x}}$, the colloidal stability of the AuNPs and hence the color of the suspension reflects the affinity and coordination number of the compounds interacting and forming complexes with $\mathrm{Zn}^{2+}$. ${ }^{28}$

The $\mathrm{Zn}^{2+}$-triggered AuNP aggregation is highly specific and the result of a $\mathrm{Zn}^{2+}$-dependent homodimerization and folding of the immobilized polypeptides (JR2EC). ${ }^{21}$ JR2EC is a 42 residue helix-loop-helix polypeptide designed to homodimerize and fold into a molten globule-like antiparallel four-helix bundle when subjected to $\mathrm{Zn}^{2+}$. The folding is primarily driven by the burial of non-polar residues resulting in a formation of a hydrophobic core. The peptide contains a large number of glutamic acid residues mainly situated at the dimerization interface. At a neutral $\mathrm{pH}$ these residues give the peptide a net charge of -5 and charge-repulsion between monomers effectively prevents homodimerization. The addition of $\mathrm{Zn}^{2+}$ decreases the charge-repulsion, and folding and the subsequent homodimerization are induced. ${ }^{21}$ The peptides were immobilized on citrate stabilized AuNPs via a cysteine residue in the loop region, yielding particles with a remarkably high colloidal stability. ${ }^{16}$ By exposing the polypeptide functionalized particles (JR2EC-AuNPs) to millimolar concentrations of $\mathrm{Zn}^{2+}$ a dramatic and immediate aggregation is induced. The aggregation is a result of the joint coordination of $\mathrm{Zn}^{2+}$ by peptides immobilized on separate AuNPs, resulting in a folding-dependent supramolecular nanoparticle bridging. The concomitant LSPR shift saturates in a matter of minutes and can be monitored spectroscopically by tracking the change in the position of the plasmon band maximum $\left(\Delta \lambda_{\max }\right)$. We have previously employed this highly controllable $\mathrm{Zn}^{2+}$-induced aggregation in combination with synthetic receptors for colorimetric detection of proteins and for studies of the mechanism of $\mathrm{Zn}^{2+}$ coordination between proteins and biologically relevant low molecular weight chelants. ${ }^{17}, 28 \mathrm{By}$ exploiting the enzymatic hydrolysis of $\mathrm{PP}_{\mathrm{x}}$ to regulate the $\mathrm{Zn}^{2+}$ concentration and thus the stability of the AuNPs we have found an attractive route for monitoring the activity of a wide range of phosphatases and which is not restricted to the use of a specific substrate. We further envision that this novel approach to modulate nanoparticle stability can be used not only for sensing of phosphatase activity but to monitor virtually any chemical reaction that demonstrate a difference in the $\mathrm{Zn}^{2+}$ chelating properties of the starting materials and the resulting products. This inherent flexibility, combined with the possibilities to rapidly monitor enzymatic activity on natural substrates with high sensitivity using low-cost equipment, make this technology highly suitable for a range of applications including diagnostics and high throughput drug screening.

\section{Results and discussion}

We modified AuNPs with the zinc responsive polypeptide JR2EC to obtain a hybrid material that enabled us to monitor phosphatase-triggered changes in $\mathrm{Zn}^{2+}$ concentration by means of the associated effects on the colloidal stability of the nanoparticles. JR2EC was immobilized on $20 \mathrm{~nm}$ citrate stabilized AuNPs using the cysteine residue in the loop region. Unbound polypeptides were removed by repeated centrifugations and resuspension in Bis-tris buffer $(30 \mathrm{mM}, \mathrm{pH}$ 7 ) until the concentration of polypeptides in solution was lower than $5 \mathrm{pM}$. Unmodified AuNPs subjected to this treatment aggregated extensively and non-reversibly whereas the peptide functionalized AuNPs displayed excellent colloidal stability as a result of efficient electrosteric stabilization by the highly negatively charged JR2EC. JR2EC-AuNPs aggregated rapidly but reversibly when exposed to $\mathrm{Zn}^{2+}$ concentrations $>1 \mathrm{mM}$, causing a red shift of the LSPR band from $\sim 527 \mathrm{~nm}$ to $\sim 610 \mathrm{~nm}$ (Figure 1a), resulting in a clearly visible color change of the suspension. The particles went from a completely dispersed state to a state of extensive aggregation in a narrow $\mathrm{Zn}^{2+}$ concentration range, 1-1.5 mM (Figure 1b). ${ }^{21,} 28$ Addition of $\mathrm{Zn}^{2+}$ coordinating compounds can reduce the concentration of $\mathrm{Zn}^{2+}$ available to the peptide, which consequently affect the aggregation. One such compound capable of sequestering $\mathrm{Zn}^{2+}$ is inorganic phosphate $\left(\mathrm{P}_{\mathrm{i}}\right)$, which forms insoluble $\left[\mathrm{Zn}_{3}\left(\mathrm{PO}_{4}\right)_{2}\right]$ 


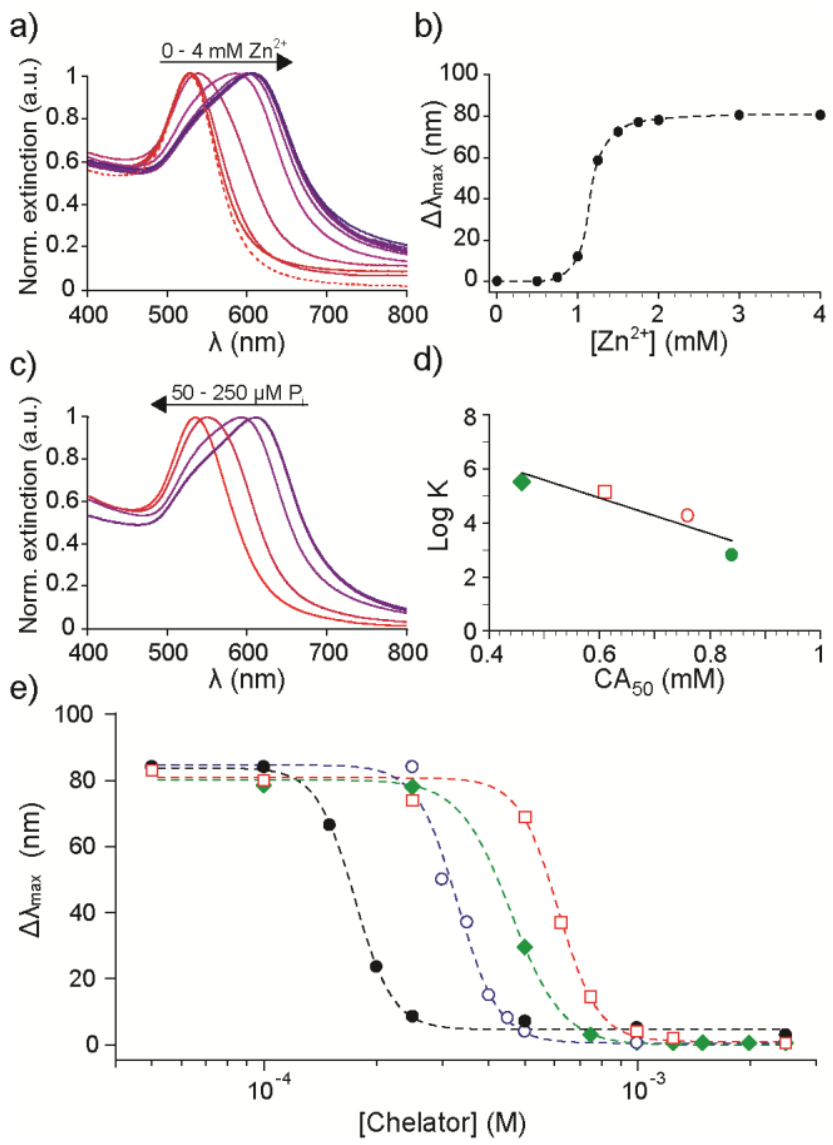

Figure 1 a) UV-vis spectra of JR2EC-AuNPs in the presence of increasing concentrations of $\mathrm{Zn}^{2+}$, from $0 \mathrm{mM}$ (broken line) to $4 \mathrm{mM}$. b) Change in the position of the LSPR peak maximum $\left(\Delta \lambda_{\max }\right)$ as a function of increasing $\mathrm{Zn}^{2+}$ concentration, from $0 \mathrm{mM}$ to $4 \mathrm{mM}$. c) UV-vis spectra of JR2EC-AuNPs upon addition of $P_{i}(50-250 \mu M)$ in the presence of $2 \mathrm{mM} \mathrm{Zn}^{2+}$. d) Linear correlation between $\log \mathrm{K}$ and $\mathrm{CA}_{50}$ for GTP $(\bullet)$, ATP $(\square)$, ADP (o) and GMP $(\bullet)$ which all interact in a 1:1 stoichiometry with $\mathrm{Zn}^{2+}$. e) $\Delta \lambda_{\max }$ as a function of $\left[\mathrm{P}_{\mathrm{i}}\right](\bullet),\left[\mathrm{PP}_{\mathrm{i}}\right]$ (०), [GTP] ( $\bullet$ ) and [ATP] ( $\square$ ) in a buffer containing $2 \mathrm{mM} \mathrm{Zn}^{2+}$. Lines in b) and e) were obtained by fitting data to a monophasic Hill equation.

complexes with a logarithmic solubility product constant (log $\mathrm{K}_{\mathrm{sp}}$ ) of $-31.49 .{ }^{29}$ Sufficiently high concentrations of $\mathrm{P}_{\mathrm{i}}$ can efficiently deprive the immobilized polypeptides of $\mathrm{Zn}^{2+}$, preventing aggregation.

When keeping the concentration of $\mathrm{Zn}^{2+}$ constant at $2 \mathrm{mM}$, which in the absence of competing chelators is high enough to cause massive aggregation, a gradual decrease in aggregation was observed with increasing concentration of $\mathrm{P}_{\mathrm{i}}$ from $100 \mu \mathrm{M}$ to $250 \mu \mathrm{M}$ (Figure $1 \mathrm{c}$ and e). At $250 \mu \mathrm{M} \mathrm{P}_{\mathrm{i}}$ the particles were completely dispersed. Considering the stoichiometry of forming $\mathrm{Zn}_{3}\left(\mathrm{PO}_{4}\right)_{2}$, this amount of $\mathrm{P}_{\mathrm{i}}$ will reduce the $\mathrm{Zn}^{2+}$ concentration in solution to about $1.63 \mathrm{mM}$, which in the absence of $\mathrm{P}_{\mathrm{i}}$ is still enough to induce extensive aggregation (Figure 2b). The prevention of the normal mode of aggregation did thus occur at a lower concentration of $\mathrm{P}_{\mathrm{i}}$ than to be expected by the decrease in the $\mathrm{Zn}^{2+}$ concentration alone (Figure $\mathrm{S} 1$ ). We have recently shown that chelants with a coordination number of $>1$ and capable of forming ternary complexes with $\mathrm{Zn}^{2+}$ can share the metal ion with the peptide. These interactions result in formation of a network polynuclear complexes that are tethered to the nanoparticle surface via the peptide-associated $\mathrm{Zn}^{2+}$ and which consequently interferes with peptide dimerization and prevents the folding induced aggregation. ${ }^{28}$ In addition to the decrease in the concentration of available $\mathrm{Zn}^{2+}$, the aggregation is thus likely affected by the formation of ternary complexes involving JR2EC as a ligand that share the $\mathrm{Zn}^{2+}$ with $\mathrm{P}_{\mathrm{i}}$ in order to create a full coordination sphere. The polypeptide- $\mathrm{Zn}^{2+}-\mathrm{P}_{\mathrm{i}}$ complex can then anchor $\left[\mathrm{Zn}_{3}\left(\mathrm{PO}_{4}\right)_{2}\right]$ complexes to the nanoparticle surface.

A similar effect was observed for $\mathrm{PP}_{\mathrm{i}}$ but the concentration required to completely prevent aggregation was significantly higher. This difference can be illustrated by comparing the concentration of coordination agent required to reduce the maximum LSPR response by $50 \%$ (CA50), which was $0.17 \mathrm{mM}$ and $0.33 \mathrm{mM}$ for $\mathrm{P}_{\mathrm{i}}$ and $\mathrm{PP}_{\mathrm{i}}$ respectively. These values were obtained by fitting the data in Figure 1e) to a monophasic Hill equation (Supporting Information). $\mathrm{PP}_{\mathrm{i}}$ forms complexes with $\mathrm{Zn}^{2+}$ predominantly in the soluble form of $\left[\mathrm{Zn}^{2+}\left(\mathrm{PP}_{\mathrm{i}}\right)_{2}\right]^{6-}$ with a logarithmic stability constant (log K) of 11.0. ${ }^{25}$ The lower $\mathrm{Zn}^{2+}$ affinity and stoichiometry explains the lower $\mathrm{CA}_{50}$ value obtained for $\mathrm{PP}_{\mathrm{i}}$ as compared to $\mathrm{P}_{\mathrm{i}}$. The presence of both $\mathrm{P}_{\mathrm{i}}$ and $\mathrm{PP}_{\mathrm{i}}$ could thus easily be detected and discriminated using this plasmonic assay because the latter was required in significantly higher concentrations to prevent nanoparticle aggregation (Figure 1 e).

This is particularly interesting since both species are generated as byproducts in numerous critically important enzymatic reactions. For example, $P_{i}$ can be generated by hydrolysis of NTPs such as ATP and GTP. Both ATP and GTP, as well as nucleotide mono- and di-phosphates, form monomeric complexes with divalent metal ions, albeit with lower affinity than $\mathrm{P}_{\mathrm{i}}$ and $\mathrm{PP}_{\mathrm{i}}$. The stability and solubility constants for the complex formation between $\mathrm{Zn}^{2+}, \mathrm{Mg}^{2+}, \mathrm{Ca}^{2+}$ and these species are summarized in Table 1 . The coordination of $\mathrm{Zn}^{2+}$ by ATP and GTP was clearly visualized using the polypeptide functionalized AuNPs (Figure 1e). GTP, which has slightly higher affinity for $\mathrm{Zn}^{2+}$ than ATP, was indeed found to prevent the $\mathrm{Zn}^{2+}$ triggered aggregation to a larger extent than ATP, with a $\mathrm{CA}_{50}$ of $0.46 \mathrm{mM}$ and $0.61 \mathrm{mM}$ for GTP and ATP, respectively (Figure 1e). ${ }^{26}$ The same trend was observed for adenosine 5'-diphosphate (ADP), guanosine 5'-monophosphate (GMP), adenosine 5'-monophosphate (AMP), and adenosine, where higher concentrations were required to prevent aggregation as the affinity for $\mathrm{Zn}^{2+}$ decreased (Table 1 and Figure S2). ${ }^{30,} 31$ AMP was however insoluble at the concentrations required to completely prevent aggregation, but initially showed the same trend. The nucleoside adenosine had a negligible influence on the stability of the JR2EC-AuNPs, since the affinity was too low to deprive the polypeptide of enough $\mathrm{Zn}^{2+}$ to affect the aggregation. A linear correlation was found between the $\log \mathrm{K}$ value and $\mathrm{CA}_{50}$ for the species that formed monomeric complexes with $\mathrm{Zn}^{2+}$ (GTP, ATP, ADP and GMP) and that could prevent the aggregation (Figure 1d), demonstrating the clear correlation between the solubility constant and the $\mathrm{CA}_{50}$ value. 
Table 1. Stability and solubility constants and $\mathrm{CA}_{50}$ values for complexes

\begin{tabular}{|c|c|c|c|c|c|c|c|c|}
\hline & \multicolumn{3}{|c|}{$\log \mathrm{K}^{\mathrm{a})}$} & \multicolumn{3}{|c|}{$\log K_{\mathrm{sp}}$ b) } & \multirow[t]{2}{*}{ Ref. } & \multirow[t]{2}{*}{$\mathrm{CA}_{50}[\mathrm{mM}]^{\mathrm{c}}$} \\
\hline & $\mathrm{Zn}^{2+}$ & $\mathrm{Mg}^{2+}$ & $\mathrm{Ca}^{2+}$ & $\mathrm{Zn}^{2+}$ & $\mathrm{Mg}^{2+}$ & $\mathrm{Ca}^{2+}$ & & \\
\hline ATP & 5.16 & 4.29 & 3.91 & - & - & - & 26 & 0.61 \\
\hline ADP & 4.28 & 3.36 & 2.95 & - & - & - & 30 & 0.76 \\
\hline AMP & 2.38 & 1.62 & 1.48 & - & - & - & 30 & - \\
\hline Adenosine & 0.24 & - & - & - & - & - & 30 & - \\
\hline GTP & 5.52 & 4.31 & 3.96 & - & - & - & 26 & 0.46 \\
\hline GMP & 2.65 & 1.54 & 1.73 & - & - & - & 31 & 0.84 \\
\hline$P_{i}$ & - & - & - & -31.49 & -25 & -32.68 & 29 & 0.17 \\
\hline $\mathrm{PP}_{\mathrm{i}}$ & 11.0 & - & - & - & - & - & 25 & 0.33 \\
\hline
\end{tabular}

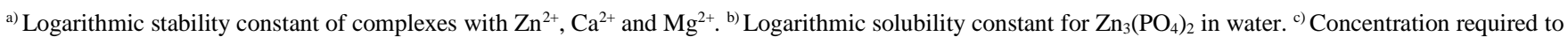
reduce the maximum $\mathrm{Zn}^{2+}$-response by $50 \%$.

It should be mentioned that the Bis-Tris buffer used here also can coordinate $\mathrm{Zn}^{2+}$ to a certain extent and has been found to stabilize ATP- $\mathrm{Zn}^{2+}$ complexes as an additional ligand. ${ }^{26}$ This effect will however not influence the ability of the system to detect changes in the total $\mathrm{Zn}^{2+}$ coordination capacity of the sample as a result of enzymatic hydrolysis of NTP.

\section{Plasmonic detection of phosphatase activity}

$\mathrm{PP}_{\mathrm{x}}$ are common substrates in numerous enzyme-regulated reactions where the high-energy ester bonds are hydrolyzed to yield 2-3 $\mathrm{P}_{\mathrm{i}}$ for each substrate. The number of $\mathrm{P}_{\mathrm{i}}$ generated is dependent on the substrate and the particular enzyme involved. We investigated three different enzymes; alkaline phosphatase (ALP), pyrophosphatase (PPase) and apyrase, using five different substrates (ATP, ADP, AMP, GTP, and $\mathrm{PP}_{\mathrm{i}}$ ) in order to validate the hypothesis that the proposed system can be utilized as a generic sensing strategy for monitoring enzymatic processes generating $P_{i}$ (Figure 2a).

a)
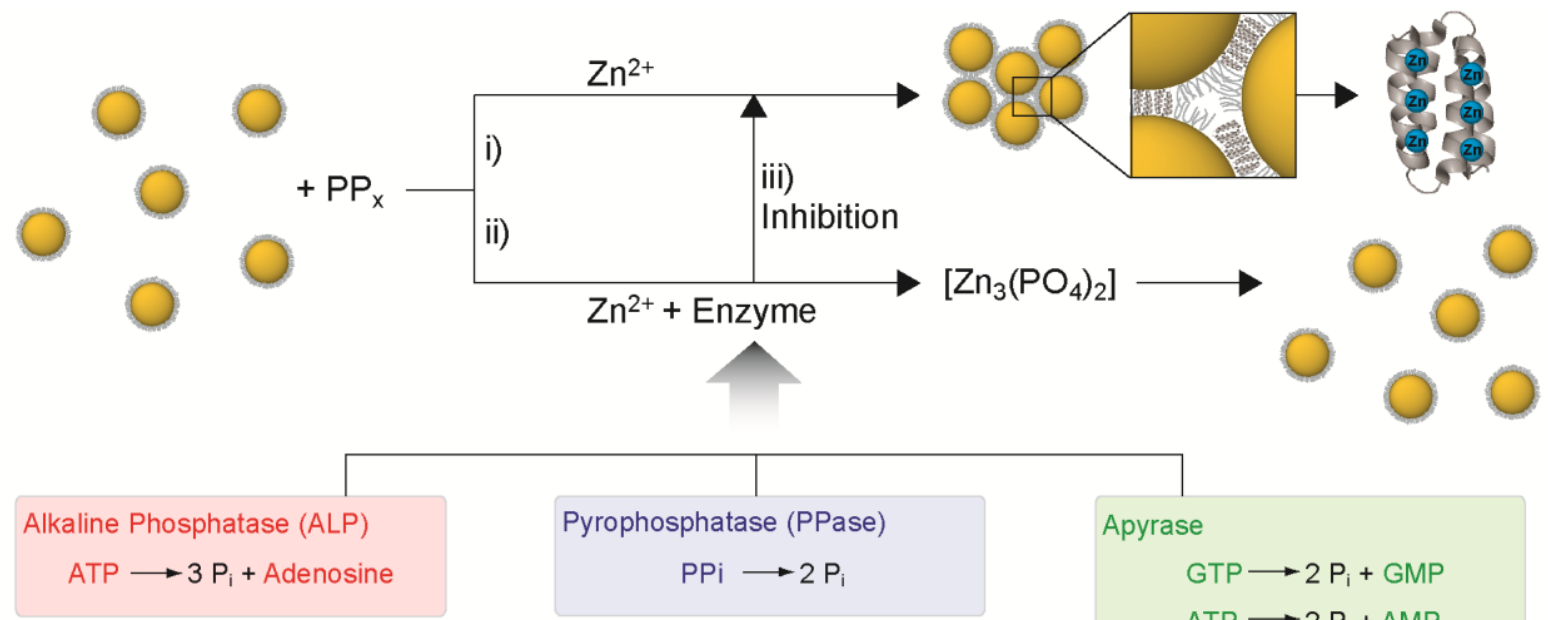

b)

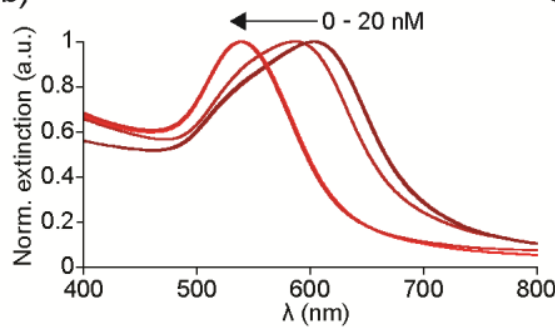

c)

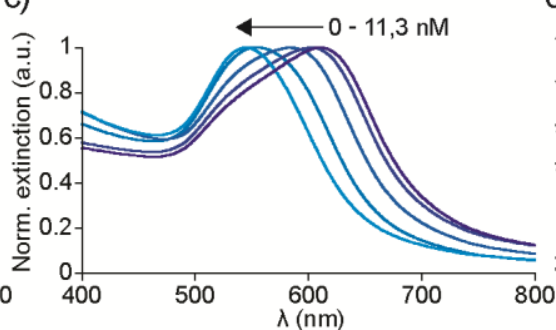

d)
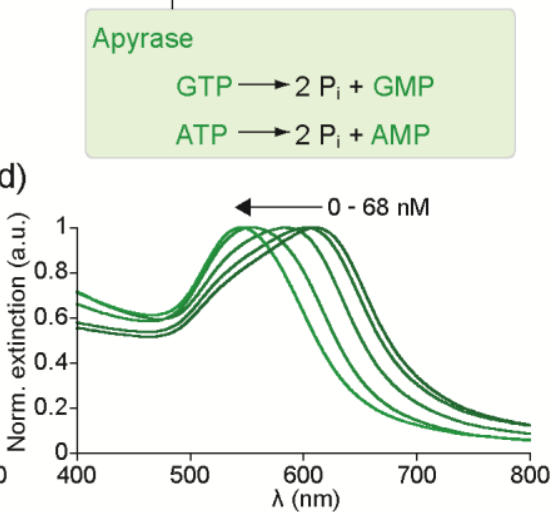

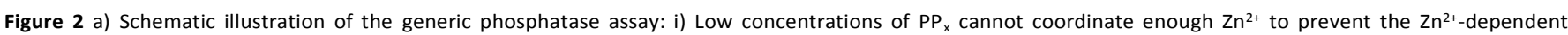

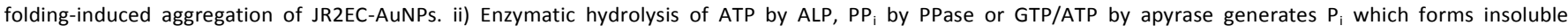

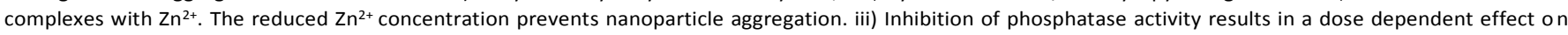

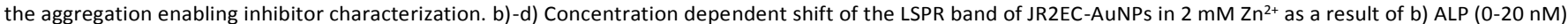

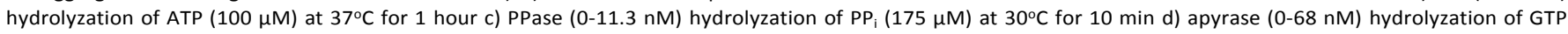
$(250 \mu \mathrm{M})$ at $30^{\circ} \mathrm{C}$ for 2.5 hours. 
a)
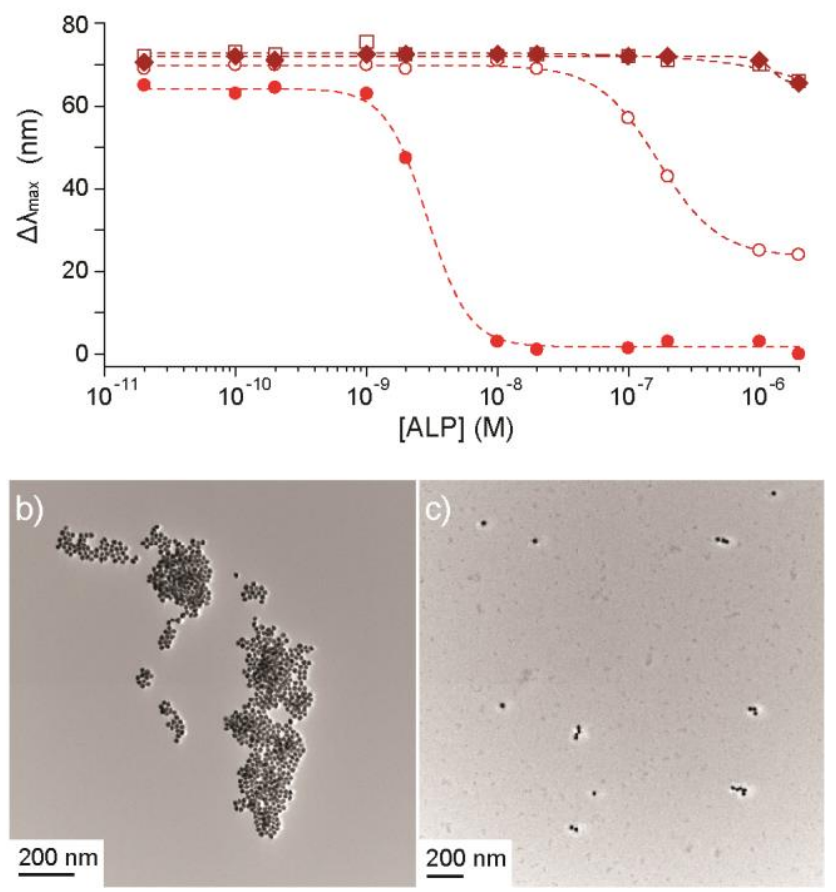

Figure 3 a) ALP concentration dependent LSPR peak shifts of JR2EC-AuNPs in 2 $\mathrm{mM} \mathrm{Zn}{ }^{2+}$ and $100 \mu \mathrm{M}$ ATP $(\bullet), \operatorname{ADP}(0), \operatorname{AMP}(\bullet)$ or adenosine ( $\left.\square\right)$. b) and c) Transmission electron micrographs of JR2EC-AuNPs in the presence of (b) $2 \mathrm{mM}$ $\mathrm{Zn}^{2+}$ and $100 \mu \mathrm{M}$ ATP and (c) $20 \mathrm{nM}$ ALP pre-incubated with $100 \mu \mathrm{M}$ ATP for 30 $\mathrm{min}$ at $37^{\circ} \mathrm{C}$ prior to addition of $2 \mathrm{mM} \mathrm{Zn^{2+ }}$ and JR2EC-AuNPs.

ALP catalyzes the dephosphorylation of ATP yielding a maximum of $3 \mathrm{P}_{\mathrm{i}}$ per ATP (Figure $2 \mathrm{a}$ ). The ALP activity was monitored by incubating ATP $(100 \mu \mathrm{M})$ with ALP $(0-20 \mathrm{nM})$ in a Tris buffer (50 mM, pH 9) containing $1 \mathrm{mM} \mathrm{Mg}^{2+}$ for 1 hour at $37{ }^{\circ} \mathrm{C}$ prior to addition to a buffer containing $2 \mathrm{mM}$ $\mathrm{Zn}^{2+}$ and JR2EC-AuNPs (70 pM). The shift in the LSPR band was approximately $65 \mathrm{~nm}$ from lowest to highest concentration of ALP yielding almost completely dispersed particles at $10 \mathrm{nM}$ ALP (Figure 2b). No effect on the aggregation was observed in the absence of ALP $\left(100 \mu \mathrm{M}\right.$ ATP and $\left.2 \mathrm{mM} \mathrm{Zn}^{2+}\right)$ or in the absence of ATP ( $2 \mu \mathrm{M}$ ALP and $2 \mathrm{mM} \mathrm{Zn}^{2+}$ ) (Figure S3), which clearly demonstrates that the combination of both ALP and ATP was required to prevent the $\mathrm{Zn}^{2+}$-triggered nanoparticle aggregation and that the effect was indeed specific. ALP activity required addition of the cofactor $\mathrm{Mg}^{2+}$ $(50 \mu \mathrm{M})$. The stability constants of complexes between $\mathrm{Mg}^{2+}$ and ATP, ADP and AMP are about one order of magnitude lower than the corresponding interactions with $\mathrm{Zn}^{2+}$ (Table 1) and will thus not significantly affect the formation of $\mathrm{Zn}^{2+}$ complexes. ${ }^{26,30} \mathrm{Mg}^{2+}$ can also form complexes with $\mathrm{P}_{\mathrm{i}}$ but these are about 6 orders of magnitude more soluble than the corresponding $\mathrm{Zn}^{2+}$ complex. ${ }^{29}$ Moreover, $\mathrm{Mg}^{2+}$ does not induce folding of JR2EC and the addition the $\mathrm{Mg}^{2+}$ concentrations required for ALP activity did hence not influence the detection mechanism ensuring that $\mathrm{Zn}^{2+}$ was the main stability modulator. ${ }^{21}$, a)

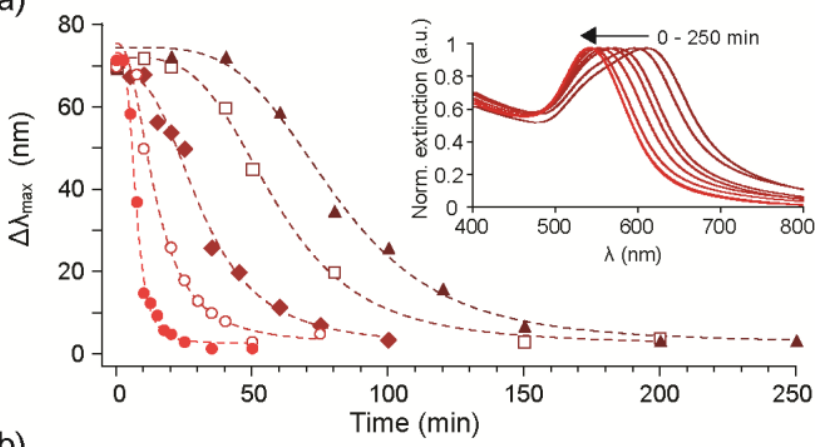

b)
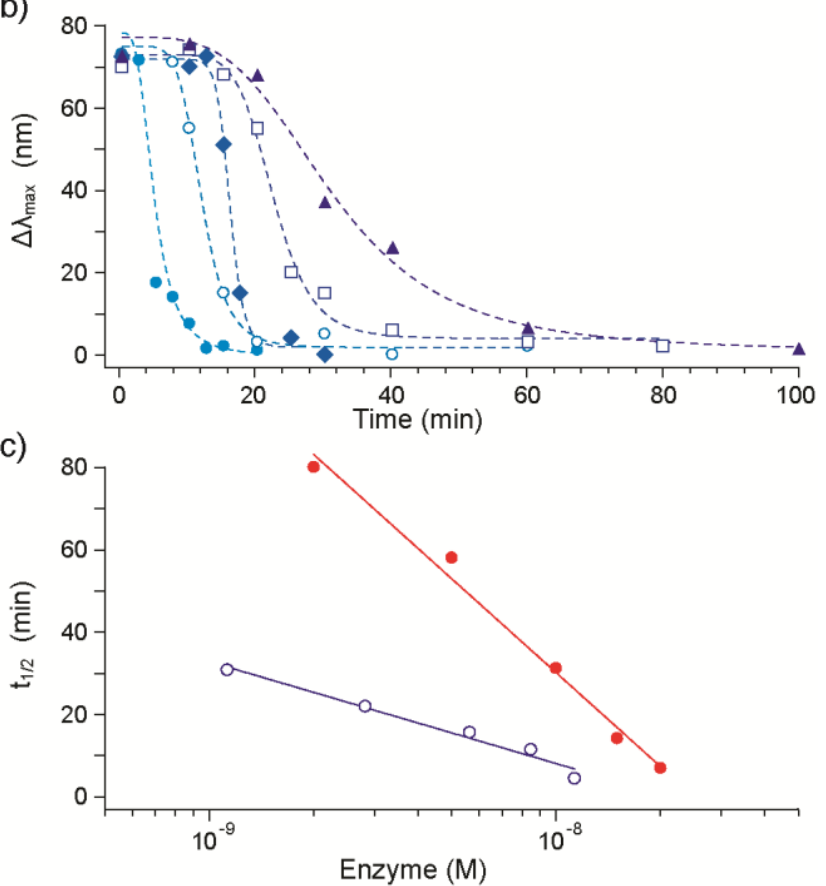

Figure 4 a) Time dependent LSPR peak shifts of JR2EC-AuNPs after exposure to 2 $\mathrm{mM} \mathrm{Zn}{ }^{2+}, 100 \mu \mathrm{M}$ ATP and $2(\boldsymbol{\Delta}), 5(\square), 10(\bullet), 15(0)$ and $20 \mathrm{nM}(\bullet)$ ALP. Inset: Time dependent shift (0-250 min) of the LSPR band of JR2EC-AuNPs in $2 \mathrm{mM} \mathrm{Zn^{2+ }}$ as a result of $2 \mathrm{nM}$ ALP hydrolyzation of ATP $(100 \mu \mathrm{M}$ at $\mathrm{t}=0 \mathrm{~min})$ at $37^{\circ} \mathrm{C}$. b) Time dependent LSPR peak shifts of JR2EC-AuNPs as a result of exposure to 2 $\mathrm{mM} \mathrm{Zn}{ }^{2+}$ and samples containing $175 \mu \mathrm{M} \mathrm{PP}$ and $1.1(\boldsymbol{\Delta}), 2.8(\square), 5.6(\bullet), 8.5(0)$ and $11.3 \mathrm{nM}(\bullet)$ PPase. Lines in a) and b) were obtained by fitting data to a monophasic Hill equation. c) Time required for obtaining 50\% LSPR response as a function of enzyme concentration for $\operatorname{ALP}\left(\bullet\right.$, red, $\left.R^{2}=0.98\right)$ and PPase $(0$, blue, $R^{2}=0.97$ ) obtained from the fitted data in a) and $b$ ).

Substituting ATP for ADP as the ALP substrate under otherwise identical conditions required a higher concentration of ALP to generate enough $\mathrm{P}_{\mathrm{i}}$ to prevent nanoparticle aggregation (Figure 3a). Because the enzymatic degradation of $100 \mu \mathrm{M}$ ADP can accumulate a maximum of $200 \mu \mathrm{M} \mathrm{P}$, the dispersion of the JR2EC-AuNPs was not complete since complete dispersion would require at least $250 \mu \mathrm{M} \mathrm{P}_{\mathrm{i}}$ (Figure 1e). A $\Delta \lambda_{\max }$ of approximately $20 \mathrm{~nm}$ was consequently obtained which is in excellent agreement with the $\Delta \lambda_{\max }$ obtained for $200 \mu \mathrm{M} \mathrm{P}_{\mathrm{i}}$ (Figure 1e), indicating that the added ADP was completely hydrolyzed within 1 hour.

When substituting ADP for AMP not enough $\mathrm{P}_{\mathrm{i}}$ was generated to prevent aggregation independently of the concentration of ALP because a maximum of $100 \mu \mathrm{M} \mathrm{P}_{\mathrm{i}}$ will result from a complete hydrolysis of AMP. Consequently, 
substituting AMP for adenosine had no impact on the modulation as no $\mathrm{P}_{\mathrm{i}}$ could be liberated. This set of experiments clearly demonstrates that the assay can be used to detect and discriminate ALP activity on all of the different natural substrates: adenosine mono-, di- and tri-phosphates, by simply utilizing an appropriate initial substrate concentration.

Transmission electron micrographs of JR2EC-AuNPs exposed to $2 \mathrm{mM} \mathrm{Zn}^{2+}$ and $100 \mu \mathrm{M}$ ATP, with and without the preceding enzymatic hydrolysis with $20 \mathrm{nM}$ ALP for $30 \mathrm{~min}$ at $37{ }^{\circ} \mathrm{C}$, further confirmed the spectroscopic observations (Figure 3 b-c). In samples not treated with ALP large JR2EC-AuNP aggregates were dominant whereas in samples treated with ALP only small aggregates and dispersed particles were present. In the former sample the corresponding $\Delta \lambda \max$ value was about $65 \mathrm{~nm}$ whereas no shift in the LSPR band was seen in the absence of ALP. In figure $3 \mathrm{c}$ ) small precipitates presumably comprised of $\left[\mathrm{Zn}_{3}\left(\mathrm{PO}_{4}\right)_{2}\right]$ are clearly seen in addition to the particles.

The ALP concentration dependent generation of $\mathrm{P}_{\mathrm{i}}$ was further characterized as a function of time. ALP (2-20 nM) was pre-incubated with ATP $(100 \mu \mathrm{M})$ for various times at $37^{\circ} \mathrm{C}$. The time required for ALP to generate enough $\mathrm{P}_{\mathrm{i}}$ to prevent nanoparticle aggregation was highly dependent on the ALP concentration (Figure 4a). The time required for obtaining a 50 $\%$ LSPR response $\left(\mathrm{t}_{1} / 2\right)$ was found to be linearly dependent of $\log$ [ALP] (Figure 4c), where the slope of the curve is directly proportional to the catalytic activity of the enzyme for the selected substrate.

a)

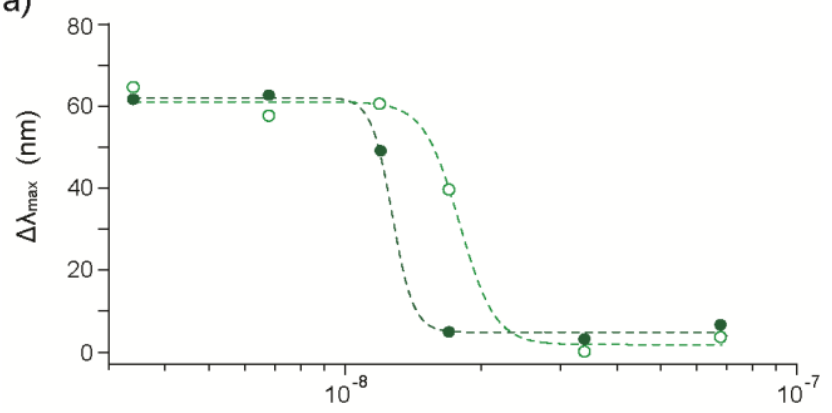

b)

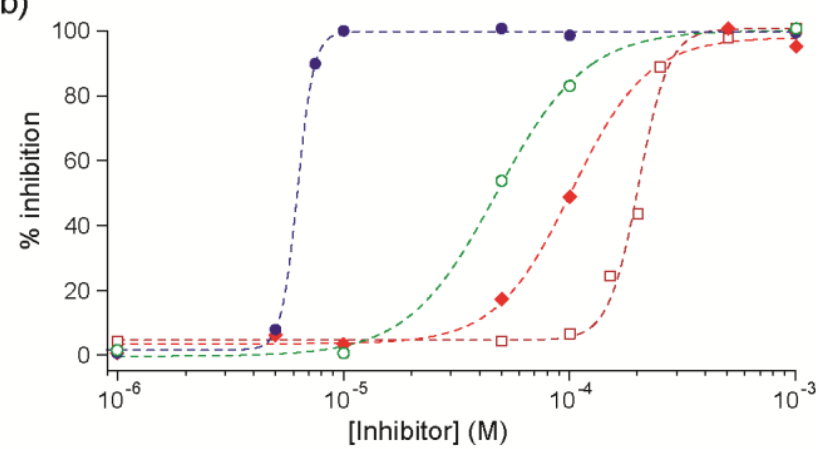

Figure 5 a) Change in LSPR peak position of JR2EC-AuNPs as a result of exposure to $2 \mathrm{mM} \mathrm{Zn}^{2+}$ and samples containing $250 \mu \mathrm{M}$ ATP $(\bullet)$ and GTP (O) incubated with 3.4-68 nM apyrase for 2.5 hours at $30{ }^{\circ} \mathrm{C}$. b) Inhibition of the three phosphatases as a function of concentration inhibitor. ALP (20 nM) was incubated with $10^{-6}-10^{-3} \mathrm{M}$ theophylline $(\bullet)$ or $\mathrm{Na}_{3} \mathrm{VO}_{4}(\square)$ and $100 \mu \mathrm{M}$ ATP for 30 $\min$ at $37{ }^{\circ} \mathrm{C}$ in a buffer containing $1 \mathrm{mM} \mathrm{Mg}^{2+}$. PPase $(11 \mathrm{nM})$ was incubated with $10^{-6}-10^{-3} \mathrm{M} \mathrm{NaF}$ and $175 \mu \mathrm{M} \mathrm{PP}$ for $10 \mathrm{~min}$ at $30^{\circ} \mathrm{C}$ in a buffer containing 1
$\mathrm{mM} \mathrm{Mg}^{2+}(\bullet)$. Apyrase $(68 \mathrm{nM})$ was incubated with $10^{-6}-10^{-3} \mathrm{M} \mathrm{GdCl}_{3}$ and $250 \mu \mathrm{M}$ GTP for 2.5 hours at $30{ }^{\circ} \mathrm{C}$ in a buffer containing $5 \mathrm{mM} \mathrm{Ca}^{2+}(0)$ before being diluted in a $2 \mathrm{mM} \mathrm{Zn}^{2+}$ containing buffer and exposed to JR2EC-AuNPs.

As the transduction mechanism is completely decoupled from the recognition event the enzymatic hydrolysis of $\mathrm{PP}_{\mathrm{i}}$ to $\mathrm{P}_{\mathrm{i}}$ by pyrophosphatase (PPase) could also be monitored using the same strategy. The hydrolysis of $\mathrm{PP}_{\mathrm{i}}$ only yields two $\mathrm{P}_{\mathrm{i}}$ as compared to three $\mathrm{P}_{\mathrm{i}}$ for degradation of ATP by ALP (Figure 2a). Consequently, a higher initial concentration of $\mathrm{PP}_{\mathrm{i}}$ was required than for the corresponding hydrolyzation of ATP by ALP to ensure that the AuNPs remained dispersed after complete hydrolysis of the substrate. The initial concentration of $\mathrm{PP}_{\mathrm{i}}$ was set to $175 \mu \mathrm{M}$ and was incubated with $0-11.3 \mathrm{nM}$ PPase in a Tris buffer (50 mM, pH 7.2) containing $1 \mathrm{mM} \mathrm{Mg}^{2+}$ at $30^{\circ} \mathrm{C}$, which are the optimal conditions for PPase, for $10 \mathrm{~min}$ prior to addition of $\mathrm{Zn}^{2+}$ and JR2EC-AuNPs (Figure 2c). No effect on the normal mode of aggregation was observed in the absence of PPase $\left(175 \mu \mathrm{M} \mathrm{PP}_{\mathrm{i}}\right.$ and $\left.2 \mathrm{mM} \mathrm{Zn}^{2+}\right)$ or in the absence of PPi (2 mM Zn ${ }^{2+}$ and $56 \mathrm{nM}$ PPase) (Figure S4). A response was only obtained when both $\mathrm{PP}_{\mathrm{i}}$ and PPase were present and the magnitude of the resulting LSPR shift was similar to that of ALP confirming that the nanoparticle aggregation was specific and the result of hydrolyzation of $\mathrm{PP}_{\mathrm{i}}$ by PPase. The enzymatic degradation of $\mathrm{PP}_{\mathrm{i}}(175 \mu \mathrm{M})$ by PPase (1.1-11.3 nM) was monitored as a function of time and PPase concentration (Figure 4b). Similarly to ALP, PPase displayed a linear correlation between $t_{1} / 2$ and $\log$ [PPase] with a slope of the curve reflecting the catalytic activity for hydrolysis of the substrate used (Figure 4c).

The flexibility of this system also enabled characterization of enzyme substrate specificity. This was demonstrated using the phosphatase apyrase that catalyzes the hydrolysis of pyrophosphate bonds from various nucleoside $\mathrm{di}^{-}$and triphosphates with the sequential release of two equivalents of $P_{i}$ (Figure 2a). ${ }^{32}$ ATP and GTP were used as substrates and the initial concentrations were set to $250 \mu \mathrm{M}$ to ensure a sufficient $P_{i}$ generation to obtain fully dispersed particles after complete substrate hydrolysis within a reasonable timeframe since apyrase has a turnover rate which is only about a third of that of ALP. ${ }^{33,34}$ The concentration of apyrase was varied from 0 to 68 $\mathrm{nM}$ and the samples were incubated in a Mes buffer $(50 \mathrm{mM}$, $\mathrm{pH}$ 6) containing $5 \mathrm{mM} \mathrm{Ca}^{2+}$ and $250 \mu \mathrm{M}$ ATP or GTP for 2.5 hours at $30^{\circ} \mathrm{C}$ prior to $\mathrm{Zn}^{2+}$ and JR2EC-AuNP exposure (Figure 2d). The LSPR peak positions were fitted to a monophasic Hill equation yielding two separated functions representing the substrate preference for ATP over GTP (Figure 5a). The concentration of apyrase required to obtain a $50 \%$ response for ATP and GTP were found to be 12.7 and $17.9 \mathrm{nM}$, respectively, giving a substrate preference for ATP by a factor 1.41. Control experiments performed in the absence of apyrase $(250 \mu \mathrm{M}$ ATP or GTP and $2 \mathrm{mM} \mathrm{Zn}^{2+}$ ) or in the absence of ATP or GTP (68

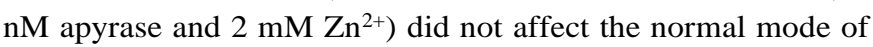
aggregation, clearly demonstrating that the LSPR response was caused by apyrase hydrolyzation of ATP or GTP and indeed specific (Figure S5). The cofactor $\mathrm{Ca}^{2+}$, present at a 
concentration of $250 \mu \mathrm{M}$, is essential for apyrase activity. $\mathrm{Ca}^{2+}$ interacts less strongly with the nucleotides and the generated products as compared to $\mathrm{Zn}^{2+}$ (Table 1), ${ }^{26,} 30$ but forms complexes with $\mathrm{P}_{\mathrm{i}}$ to the same extent as $\mathrm{Zn}^{2+}$. ${ }^{29}$ A slightly higher $\mathrm{P}_{\mathrm{i}}$ generation was consequently required in order to compensate for this interaction. The direct influence of $\mathrm{Ca}^{2+}$ on the aggregation of the polypeptide modified nanoparticles was negligible since $\mathrm{Ca}^{2+}$ does not induce folding of the polypeptides. $^{21}$

\section{Inhibitor characterization}

We then went on to investigate the applicability of the assay for inhibition studies of the selected phosphatases. At least one inhibitor was used for each phosphatase and the concentration dependent response was characterized. Control experiments for all inhibitors were performed by monitoring the effects on aggregation of individual inhibitors present at the highest concentration used in the enzyme inhibition studies, with and without $2 \mathrm{mM} \mathrm{Zn}{ }^{2+}$ (Figure S6). No inhibitor was found to influence the normal mode of aggregation or induce nanoparticle aggregation on their own. For ALP two distinctly different inhibitors were used: theophylline which is a methylxanthine drug used in therapy for respiratory disorders that inhibits ALP in an uncompetitive manner and sodium orthovanadate $\left(\mathrm{Na}_{3} \mathrm{VO}_{4}\right)$ which is a transition state analog of $\mathrm{P}_{\mathrm{i}}$ and acts as a competitive inhibitor. ${ }^{35,36}$ Both inhibitors $\left(10^{-6}-10^{-}\right.$ $\left.{ }^{3} \mathrm{M}\right)$ showed dose responsive curves when incubated with 20 nM ALP and $100 \mu \mathrm{M}$ ATP at $37^{\circ} \mathrm{C}$ for $30 \mathrm{~min}$ (Figure 5b). An IC50 value of $102 \mu \mathrm{M}$ was obtained for theophylline by fitting the data to a monophasic Hill equation, which is identical to previously reported data. ${ }^{36}$ The $\mathrm{IC}_{50}$ value of $\mathrm{Na}_{3} \mathrm{VO}_{4}$ was 202 $\mu \mathrm{M}$, which is slightly higher than previously reported values for alkaline phosphatases. ${ }^{35}$ The dose responsive inhibition of PPase by sodium fluoride (NaF, $10^{-6}-10^{-3} \mathrm{M}$ ) and that of apyrase by gadolinium chloride $\left(\mathrm{GdCl}_{3}, 10^{-6}-10^{-3} \mathrm{M}\right)$ gave $\mathrm{IC}_{50}$ values of $6.4 \mu \mathrm{M}$ and $47 \mu \mathrm{M}$ (Figure $5 \mathrm{~b}$ ), respectively, which are in good agreement with previously reported data. ${ }^{24,37}$

\section{Experimental}

MATERIALS: Alkaline phosphatase from bovine intestinal mucosa (EC 3.1.3.1), apyrase from Solanum tuberosum (EC 3.6.1.5), pyrophosphatase from Saccharomyces cerevisiae (EC 3.6.1.1), inhibitors, metal salts $\left(\mathrm{MCl}_{\mathrm{x}}\right)$, buffers and phosphate containing compounds were purchased from Sigma Aldrich and used without further purification. Citrate stabilized AuNPs with an average size of $20 \mathrm{~nm}$ was purchased from BBInternational.

PePtIDE SYNTHesis: The polypeptide JR2EC $\left(\mathrm{H}_{2} \mathrm{~N}\right.$-AADLEK AIEALEKHLEAKGPCDAAQLEKQLEQAFEAFERAG-

$\mathrm{COOH}$ ) was synthesized on a Quartet automated peptide synthesizer (Protein Technologies, Inc.) using standard fluroenylmethoxycarbonyl (Fmoc) chemistry. The synthesis was performed on a $0.1 \mathrm{mmol}$ scale with Fmoc-Gly-Wang (Iris biotech GMBH) with a substitution level of $0.77 \mathrm{mmolg}^{-1}$ as solid support. Each coupling was performed using a fourfold excess of O-(7-benzotriazole-1-yl)-1, 1, 3, 3-tetra- methyluronium tetrafluoroborate, (TBTU, Iris biotech GMBH) as activator and an eightfold excess of diisopropylamine (DIPEA, Iris biotech GMBH) as base. A fourfold excess of amino acid (Iris biotech GMBH) was used in each coupling and subsequent deprotection of the coupled amino acid was accomplished by treatment with piperidine in DMF $(20 \%$, Applied Biosystems). Side chain deprotection and cleavage from the solid support was accomplished by exposure to a solution containing trifluoroacetic acid (TFA), ethandithiol, water and triisopropylsilane (TIS) (94:2.5:2.5:1, v/v/v/v) 15 $\mathrm{mLg}^{-1}$ of polymer for 2 hours followed by filtration and evaporation of the solvent. The crude peptide was precipitated twice in cold diethylether and then lyophilized. Purification of the crude peptide was carried out using a 30 minute gradient of $30-41 \%$ aqueous isopropanol with $0.1 \%$ TFA on an ACE 5 C8 column $(250 \times 21.2 \mathrm{~mm})$ attached to a semi-preparative HPLC system (Dionex). The identity of the purified peptide was confirmed by MALDI-TOF MS using an $\alpha$-cyano-4hydroxycinnamic acid matrix.

GOLD NANOPARTICLE FUNCTIONALIZATION: JR2EC functionalized AuNPs were acquired by incubating $10 \mu \mathrm{M}$ JR2EC (10 mM sodium citrate, $\mathrm{pH} \mathrm{6)}$ with $~ 70 \mathrm{nM}$ AuNPs for at least 18 hours at $4^{\circ} \mathrm{C}$. The AuNPs were then repeatedly centrifuged and the supernatant was exchanged for Bis-Tris buffer $(30 \mathrm{mM}, \mathrm{pH} 7.0)$, this procedure was repeated until the concentration of non-immobilized JR2EC was below 5 pM. The final concentration of the functionalized AuNPs was estimated to be approximately $6.8 \mathrm{nM}$ using the absorbance at $526 \mathrm{~nm}$ and an extinction coefficient of $1.57 \times 10^{9} \mathrm{M}^{-1} \mathrm{~cm}^{-1} .38$

Colorimetric detection of PHOSPhatase ACTIVITY AND INHIBITION: A colorimetric assay for enzymatic dephosphorylation / inhibition was performed as follows:

Alkaline Phosphatase (ALP): ATP $(5 \mu \mathrm{l}, 20 \mathrm{mM}$, in MQwater) and $10 \mu \mathrm{ALP}(0.01-50 \mu \mathrm{M}$, in $50 \mathrm{mM}$ Tris buffer, $\mathrm{pH}$ 9) was added to a Tris buffer ( $50 \mathrm{mM}, \mathrm{pH} 9)$ containing $1 \mathrm{mM}$ $\mathrm{MgCl}_{2}$ giving a final volume of $50 \mu \mathrm{l}$. The samples were incubated in a water bath for $0-250 \mathrm{~min}$ at $37^{\circ} \mathrm{C}$. In the case of an inhibition experiment $5 \mu \mathrm{l}$ of the inhibitor $\left(10^{-5}-10^{-2} \mathrm{M}\right)$ was added to the reaction mixture pre-incubation and then incubated for $30 \mathrm{~min}$ at $37^{\circ} \mathrm{C}$.

Pyrophosphatase (PPASe): Pyrophosphate $(8.75 \mu 1,20 \mathrm{mM}$, in MQ-water) and $10 \mu \mathrm{l}$ PPase (5.5-280 nM, in $50 \mathrm{mM}$ Tris buffer, $\mathrm{pH}$ 7.2) was added to a Tris buffer (50 mM, pH 7.2) containing $1 \mathrm{mM} \mathrm{MgCl} 2$ giving a final volume of $50 \mu \mathrm{l}$. The samples were incubated in a water bath for $0-100 \mathrm{~min}$ at 30 ${ }^{\circ} \mathrm{C}$. In the case of an inhibition experiment $5 \mu \mathrm{l}$ of the inhibitor $\left(10^{-5}-10^{-2} \mathrm{M}\right)$ was added to the reaction mixture pre-incubation and then incubated for $10 \mathrm{~min}$ at $30^{\circ} \mathrm{C}$.

APYRASE: GTP $(12.5 \mu \mathrm{l}, 20 \mathrm{mM}$, in MQ-water) and $10 \mu \mathrm{l}$ apyrase (17-340 $\mathrm{nM}$, in $50 \mathrm{mM}$ Mes buffer, $\mathrm{pH}$ 6) was added to a Mes buffer ( $50 \mathrm{mM}, \mathrm{pH}$ 6) containing $5 \mathrm{mM} \mathrm{CaCl} 2$ giving a final volume of $50 \mu \mathrm{l}$. The samples were incubated in a water bath for $0-180 \mathrm{~min}$ at $30{ }^{\circ} \mathrm{C}$. In the case of an inhibition experiment $5 \mu \mathrm{l}$ of the inhibitor $\left(10^{-5}-10^{-2} \mathrm{M}\right)$ was added to the reaction mixture pre-incubation and then incubated for $180 \mathrm{~min}$ at $30{ }^{\circ} \mathrm{C}$. 
Colorimetric detection: The sample $(50 \mu \mathrm{l})$ incubated as above was added to $740 \mu \mathrm{l}$ of Bis-Tris buffer (30 mM, pH 7) followed by addition of $10 \mu \mathrm{l}$ JR2EC-AuNPs $(6.8 \mathrm{nM})$. Bis-Tris buffer (200 $\mu \mathrm{l}, 30 \mathrm{mM}, \mathrm{pH} 7)$ containing $10 \mathrm{mM} \mathrm{ZnCl}_{2}$ was added and the sample was incubated at room temperature for 20 min before UV-vis measurements.

Characterization: UV-vis measurements were performed in room temperature on a SHIMADZU UV-2450 spectrophotometer with a $0.5 \mathrm{~nm}$ resolution. TEM images were acquired using a Tecnai G2 F20U-Twin microscope operating at $200 \mathrm{kV}$. Carbon coated TEM grids were prepared by applying $15 \mu \mathrm{L}$ of sample and incubating for $30 \mathrm{~min}$ before removal of excess sample using filter paper.

\section{Conclusions}

We have developed a generic and flexible colorimetric AuNPbased strategy for monitoring the enzymatic hydrolysis of $\mathrm{PP}_{\mathrm{x}}$ (ATP, ADP, AMP, GTP and $\mathrm{PP}_{\mathrm{i}}$ ) by phosphatases where the substrate recognition is completely decoupled from the nanoparticle stability modulation mechanism. This strategy enables detection of a wide range of enzymes using different natural, non-modified, substrates with a single detection system. The enzymatic reactions were transduced into a readily detectable optical signal using gold nanoparticles functionalized with a $\mathrm{Zn}^{2+}$-responsive polypeptide. The nanoparticles aggregated when exposed to $\mathrm{Zn}^{2+}$ in the concentration range 1.5 $-2 \mathrm{mM}$, caused by a polypeptide folding-induced bridging that was triggered by the coordination of $\mathrm{Zn}^{2+}$ by the peptide. PPx and $\mathrm{Pi}$ also coordinate $\mathrm{Zn}^{2+}$, and their presence interfered with the polypeptide folding and thus the nanoparticle aggregation. The various phosphatase substrates $\left(\mathrm{PP}_{\mathrm{x}}\right)$ and the enzymatically generated byproduct phosphate $\left(\mathrm{P}_{\mathrm{i}}\right)$ showed significant differences in coordination capacity for $\mathrm{Zn}^{2+}$. Using this $\mathrm{Zn}^{2+}$ responsive polypeptide-nanoparticle hybrid system the enzymatic hydrolyzation of $\mathrm{PP}_{\mathrm{x}}$ could be monitored in real time by exploiting the large shifts in the localized surface plasmon resonance band as an indicator of enzymatic activity. The flexibility of this sensing strategy was evaluated using three completely different phosphatases; alkaline phosphatase, pyrophosphatase and apyrase that catalyze the enzymatic degradation of ATP, PPi and GTP/ATP, respectively. All three enzymes could be detected in the low nanomolar range. Importantly, no interference from different metal cation cofactors was observed because of the preference of the polypeptide for coordinating $\mathrm{Zn}^{2+}$. We also investigated the possibility to use this detection strategy for characterization of both enzyme substrate specificity and effects of inhibitors on enzymatic activity using different enzymes and substrates. The flexibility and versatility of this strategy clearly demonstrate the benefit of decoupling the biomolecular recognition event and the mechanism for nanoparticle stability modulation. The general applicability of this approach for detection of phosphatase activity, and for characterization of substrate specificity and phosphatase inhibitors is expected to be of significant value for the development of novel diagnostic assays and high-throughput drug screening.

\section{Acknowledgements}

The authors acknowledge the financial support from Linköping University, the Swedish Research Council (VR), the Swedish Foundation for Strategic Research (SSF), the Knut and Alice Wallenberg Foundation (KAW) and the Centre in Nanoscience and Technology (CeNano). We thank Erik Martinsson for help with graphics. During this study R.S. was enrolled in the graduate school Forum Scientium.

\section{Notes and references}

Division of Molecular Physics, Department of Physics, Chemistry and Biology, Linköping University, SE-583 36 Linköping, Sweden E-mail: daniel.aili@liu.se

Electronic Supplementary Information (ESI) available: See DOI: $10.1039 / \mathrm{b} 000000 \mathrm{x} /$

1. G. Burnstock, Trends Pharmacol. Sci., 2006, 27, 166.

2. H. A. Praetorius and J. Leipziger, Annu. Rev. Physiol., 2010, 72, 377.

3. C. A. Parent and P. N. Devreotes, Science, 1999, 284, 765.

4. E. Cabib, J. Drgonová and T. Drgon, Annu. Rev. Biochem., 1998, 67, 307.

5. W. E. Balch, Trends Biochem. Sci., 1990, 15, 473.

6. R. A. Terkeltaub, Am. J. Physiol.-Cell PH., 2001, 281, C1.

7. A. R. Saltiel and C. R. Kahn, Nature, 2001, 414, 799.

8. B. Boivin, F. Chaudhary, B. C. Dickinson, A. Haque, S. C. Pero, C. J. Chang and N. K. Tonks, J. Biol. Chem., 2013, 288, 36926.

9. S. Klumpp and J. Krieglstein, Curr. Opin. Pharmacol., 2002, 2, 458.

10. R. Q. Thompson, G. C. Barone Iii, H. B. Halsall and W. R. Heineman, Anal. Biochem., 1991, 192, 90.

11. J. S. Blum, R. H. Li, A. G. Mikos and M. A. Barry, J. Cell. Biochem., 2001, 80, 532.

12. L. Jia, J.-P. Xu, D. Li, S.-P. Pang, Y. Fang, Z.-G. Song and J. Ji, Chem. Commun., 2010, 46, 7166.

13. N. L. Rosi and C. A. Mirkin, Chem. Rev., 2005, 105, 1547.

14. D. Aili and M. M. Stevens, Chem. Soc. Rev., 2010, 39, 3358.

15. R. Wilson, Chem. Soc. Rev., 2008, 37, 2028.

16. D. Aili, M. Mager, D. Roche and M. M. Stevens, Nano Lett., 2010, 11, 1401

17. D. Aili, R. Selegard, L. Baltzer, K. Enander and B. Liedberg, Small, 2009, 5, 2445.

18. A. Laromaine, L. L. Koh, M. Murugesan, R. V. Ulijn and M. M. Stevens, J. Am. Chem. Soc., 2007, 129, 4156.

19. R. Elghanian, J. J. Storhoff, R. C. Mucic, R. L. Letsinger and C. A. Mirkin, Science, 1997, 277, 1078.

20. J.-S. Lee, M. S. Han and C. A. Mirkin, Angew. Chem., Int. Ed., 2007, 46, 4093.

21. D. Aili, K. Enander, J. Rydberg, I. Nesterenko, F. Björefors, L. Baltzer and B. Liedberg, J. Am. Chem. Soc., 2008, 130, 5780. 
22. C. M. Li, S. J. Zhen, J. Wang, Y. F. Li and C. Z. Huang, Biosens. Bioelectron., 2013, 43, 366.

23. W. Zhao, W. Chiuman, J. C. F. Lam, M. A. Brook and Y. Li, Chem. Commun., 2007, 3729.

24. J. Deng, Q. Jiang, Y. Wang, L. Yang, P. Yu and L. Mao, Anal. Chem., 2013, 85, 9409.

25. H. L. Clever, M. E. Derrick and S. A. Johnson, J. Phys. Chem. Ref. Data, 1992, 21, 941.

26. H. Sigel and R. Griesser, Chem. Soc. Rev., 2005, 34, 875.

27. H. Sigel, E. M. Bianchi, N. A. Corfù, Y. Kinjo, R. Tribolet and R. B. Martin, Chem.-Eur. J., 2001, 7, 3729.

28. M. Mak, R. Selegård, M. Garbrecht and D. Aili, Part. Part. Syst. Charact, 2014, In press.

29. F. X. Han, Biogeochemistry of trace Elements in Arid Environments, Springer, Dordrecht, 2007.

30. E. M. Bianchi, S. A. A. Sajadi, B. Song and H. Sigel, Chem.-Eur. J., 2003, 9, 881 .

31. H. A. Azab and Z. M. Anwar, J. Chem. Eng. Data, 2012, 57, 2890.

32. L. Plesner, in International Review of Cytology, eds. W. J. Kwang and J. Jonathan, Academic Press, 1995, vol. Volume 158, pp. 141.

33. A. M. Kettlun, V. Espinosa, L. García and M. A. Valenzuela, Phytochemistry, 2005, 66, 975.

34. T. Manes, M. F. Hoylaerts, R. Müller, F. Lottspeich, W. Hölke and J. L. Millán, J. Biol. Chem., 1998, 273, 23353.

35. P. J. Stankiewicz and M. J. Gresser, Biochemistry, 1988, 27, 206.

36. E. N. Fawaz and A. Tejirian, Hoppe Seylers Z. Physiol. Chem., 1972, 353, 1779.

37. A. Escalada, P. Navarro, E. Ros, J. Aleu, C. Solsona and M. MartínSatué, Neurochem. Res., 2004, 29, 1711.

38. J. Yguerabide and E. E. Yguerabide, Anal. Biochem., 1998, 262, 137. 